\title{
KOMPOSISI UKURAN, PERBANDINGAN JENIS KELAMIN, DAN TINGKAT KEMATANGAN GONAD IKAN TODAK BERPARUH PENDEK (Tetrapturus angustirostris) DI SAMUDERA HINDIA
}

\author{
Dian Novianto'), Budi Nugraha'), dan Andi Bahtiar') \\ 1) Peneliti pada Stasiun Monitoring Perikanan Tuna, Benoa-Bali \\ 2) Peneliti pada Balai Riset Perikanan Laut, Muara Baru-Jakarta \\ Teregistrasi I tanggal: 16 Mei 2010; Diterima setelah perbaikan tanggal: 20 Juli 2010; \\ Disetujui terbit tanggal: 30 Juli 2010
}

\begin{abstract}
ABSTRAK
Ikan todak berparuh pendek atau ikan tumbuk atau shortbill spearfish (Tetrapturus angustirostris) merupakan salah satu hasil tangkapan sampingan rawai tuna. Informasi mengenai ikan todak berparuh pendek seperti komposisi ukuran, perbandingan kelamin, dan tingkat kematangan gonad sangat terbatas. Tulisan ini bertujuan untuk menyajikan data dan informasi mengenai aspek biologi ikan todak berparuh pendek yang merupakan hasil tangkapan sampingan dari rawai tuna yang beroperasi di Samudera Hindia. Penelitian ini dilakukan pada bulan September sampai Desember 2008 di perairan Samudera Hindia. Hasil penelitian menunjukan bahwa ikan todak berparuh pendek memiliki kisaran panjang tubuh 135-175 cmLJFL dan modus pada kisaran 155-165 cmLJFL. Perbandingan jenis kelamin ikan jantan dan betina 1:13,5, berdasarkan atas hasil uji chi-square menunjukan bahwa rasio ikan jantan dan betina pada periode penelitian ini tidak seimbang. Pada bulan September ikan todak berparuh pendek betina didominansi oleh tingkat kematangan gonad II sebesar 66,7\%, bulan Oktober oleh tingkat kematangan gonad $V$ sebesar 46,2\%, bulan Nopember oleh tingkat kematangan gonad II sebesar 53,3\%, sedangkan pada bulan Desember oleh tingkat kematangan gonad III sebesar $42,9 \%$. Pada bulan Nopember sampai Desember terlihat bahwa tingkat kematangan gonad $\mathrm{V}$ mulai berkurang, hal ini menunjukan bahwa pada bulan Nopember sampai Desember diduga banyak ikan todak berparuh pendek betina yang sudah memijah.
\end{abstract}

KATAKUNCl: $\quad$ biologi, ikan todak berparuh pendek, Samudera Hindia

ABSTRACT: $\quad$ Size composition, sex ratio, and maturity stage of shortbill spearfish (Tetrapturus angustirostris) in the Indian Ocean. By: Dian Novianto, Budi Nugraha, and Andi Bahtiar

Shortbill Spearfish (Tetrapturus angustirostris) is one of bycatch of tuna longline. Information about shortbill spearfish on the size composition, sex ratio, and maturity stage is still very limited. The objective this paper is to present the data and information about shortbill spearfish which is a bycatch of tuna longline that operated in the Indian Ocean. Research was conducted during September until December 2008 in Indian Ocean. The results showed that the shortbill spearfish have body length about 135-175 cmLJFL and modes in 155-165 cmLJFL. Sex ratio of the male and female was 1:13.5. Based on chi-square test showed that the ratio of male and female in the period of the study was not balanced. In September, the female stage maturity was dominated by level II of $66.7 \%$, October by level V of $46.2 \%$, November by level II of $53.3 \%$, and December by level III of $42.9 \%$. During November until December showed that the maturity stage of level $V$ was decreased, this shows that in this time the female of shortbill spearfish was spawned.

KEYWORDS: biology, shortbill spearfish, Indian Ocean

\section{PENDAHULUAN}

Ikan todak berparuh pendek atau dikalangan nelayan dikenal dengan nama ikan tumbuk dan ikan layaran jarum atau shortbill spearfish (Tetrapturus angustirostris) banyak tertangkap selama pengoperasian rawai tuna di Samudera Hindia. Selain Tetrapturus angustirostris, terdapat lima spesies lain yang penyebarannya terdapat di seluruh dunia yaitu marlin putih atau white marlin (Tetrapturus albidus), marlin loreng atau striped marlin (Tetrapturus audax), ikan todak mediteranian atau mediterranean spearfish (Tetrapturus belone), roundscale spearfish (Tetrapturus georgei) dan ikan todak berparuh panjang atau longbill spearfish (Tetrapturus pfluegeri) terdapat dua spesies yang hanya terdapat di Samudera Hindia yaitu Tetrapturus angustirostris dan Tetrapturus audax (Nakamura, 1985). 
Ikan ini termasuk ke dalam spesies yang beruaya jauh (highly migratory species), menyebar di perairan tropis dan sub tropis di Samudera Hindia dan Pasifik. Meskipun beberapa orang menemukannya di Samudera Atlantik, namun diyakini spesies ini memiliki daerah pemijahan (spawning ground) di Samudera Hindia dan Pasifik. Kedalaman renang dapat mencapai $1.830 \mathrm{~m}$ dan sering ditemukan di atas lapisan termoklin (Nakamura, 1985).

Tidak ada kapal perikanan yang secara khusus menangkap ikan todak berparuh pendek, tapi ikan ini secara kebetulan sering tertangkap di kapal rawai tuna sebagai hasil tangkapan sampingan (bycatch). Menurut Uktolseja et al. (1989), analisis potensi terhadap ikan todak berparuh pendek belum pernah dilakukan. Informasi mengenai ikan todak berparuh pendek seperti komposisi ukuran, perbandingan kelamin, dan tingkat kematangan gonad sangat terbatas. Tulisan ini bertujuan untuk menyajikan data dan informasi mengenai ikan todak berparuh pendek yang merupakan hasil tangkapan sampingan dari rawai tuna yang beroperasi di Samudera Hindia.

\section{BAHAN DAN METODE}

Pengambilan contoh ikan todak berparuh pendek dilakukan pada bulan September sampai Desember 2008 berlokasi di perairan Samudera Hindia. Contoh ikan yang diamati berjumlah 58 ekor yang merupakan hasil tangkapan sampingan kapal tuna longline milik salah satu perusahaan perikanan yang berbasis di Benoa, Bali.

Pengamatan aspek biologi meliputi pengukuran panjang tubuh, perbandingan jenis kelamin, dan penentuan tingkat kematangan gonad secara visual. Pengukuran panjang tubuh dengan menggunakan kaliper yang mempunyai ketelitian sampai $0,5 \mathrm{~cm}$. Panjang tubuh yang diukur mulai dari ujung bawah mulut ikan sampai cagak ekor (lower jaw fork length/ LJFL). Identifikasi jenis ikan todak berparuh pendek dilakukan sesuai dengan Nakamura (1985); Pepperell \& Grewe (1998).

Pengujian perbandingan jenis kelamin dilakukan dengan uji chi-square (Sugiyono, 2004):

$$
\begin{aligned}
& x^{2}=\sum_{i=1}^{k} \frac{(f o-f n)^{2}}{f n} \\
& \text { di mana: } \\
& \mathrm{X}^{2}=\text { chi-square } \\
& \text { fo = frekuensi yang diobservasi } \\
& \mathrm{fn} \text { = frekuensi yang diharapkan }
\end{aligned}
$$

Penentuan tingkat kematangan gonad ikan todak berparuh pendek mengacu pada kriteria Kesteven (Bagenal \& Braum, 1968 dalam Effendie, 1997) yang dibagi dalam sembilan tingkat yaitu:

1. Dara: organ seksual sangat kecil berdekatan di bawah tulang punggung. Testes dan ovarium transparan, dari tidak berwarna sampai berwarna abu-abu. Butir-butir telur tidak terlihat dengan mata biasa.

2. Dara berkembang: testes dan ovarium jernih, abuabu kemerahan. Panjangnya setengah atau lebih sedikit dari panjang rongga bawah. Butir telur satu per satu dapat terlihat dengan kaca pembesar.

3. Perkembangan I: testes dan ovarium bentuknya bulat telur, berwarna kemerah-merahan dengan pembuluh kapiler. Gonad mengisi kira-kira setengah ruang ke bagian bawah. Telur dapat terlihat seperti serbuk putih.

4. Perkembangan II: testes berwarna putih kemerahmerahan. Untuk jantan, tidak ada sperma kalau bagian perutnya ditekan. Ovarium berwarna orange kemerah-merahan. Telur jelas dapat dibedakan, bentuknya bulat telur. Ovarium mengisi kira-kira dua per tiga ruang bawah.

5. Bunting: organ seksual mengisi ruang bawah. Testes berwarna putih, keluar tetesan sperma kalau ditekan perutnya. Telur bentuknya bulat, beberapa daripadanya jernih dan masak.

6. Mijah: telur dan sperma keluar dengan sedikit tekanan ke perut. Sebagian besar telur berwarna jernih dengan beberapa yang berbentuk bulat telur tinggal di dalam ovarium.

7. Mijah atau salin: gonad belum kosong sama sekali. Tidak ada telur yang bulat telur.

8. Salin: testes dan ovarium kosong dan berwarna merah. Beberapa telur sedang dalam keadaan dihisap kembali.

9. Pulih salin: testes dan ovarium berwarna jernih, abu-abu sampai merah.

\section{HASIL DAN BAHASAN}

\section{Klasifikasi Ikan Todak Berparuh Pendek}

Menurut Nakamura (1985), klasifikasi ikan todak berparuh pendek sebagai berikut:

Filum : Chordata

Super kelas : Gnathostomata

Kelas : Osteichthyes

Sub kelas : Actinopterygii

Infra kelas : Teleostei

Divisi : Euteleostei

Super ordo : Acanthopterygii

Ordo : Perciformes

Sub ordo : Xiphioidei

Famili : Istiophoridae 
Genus

Spesies

: Tetrapturus

Menurut Nakamura (1985); Pepperell \& Grewe (1998), ikan todak berparuh pendek memiliki ciri-ciri sebagai berikut paruh lebih pendek dibandingkan dengan ikan berparuh lain. Sirip dada kecil dan pendek kurang lebih $15 \%$ dari panjang tubuhnya serta bentuk badan memanjang dan gepeng. Terdapat dua buah sirip punggung di mana sirip punggung pertama ukurannya lebih panjang dari lebar badan di mana panjangnya sampai sirip anal kedua. Sirip punggung kedua terletak sedikit di belakang sirip anal kedua. Ikan ini memiliki dua sirip anal di mana sirip anal pertama bentuknya lebih besar dari sirip anal kedua. Sirip anal kedua mempunyai ukuran dan bentuk yang mirip dengan sirip punggung kedua. Ikan todak berparuh pendek memiliki dua sirip perut yang tipis dan panjangnya kurang lebih dua kali dari panjang sirip dada. Jarak antara anus dan sirip anal hampir sama dengan panjang sirip anal pertama. Di setiap sisi ekor terdapat keel yang berjumlah dua buah (Gambar 1).

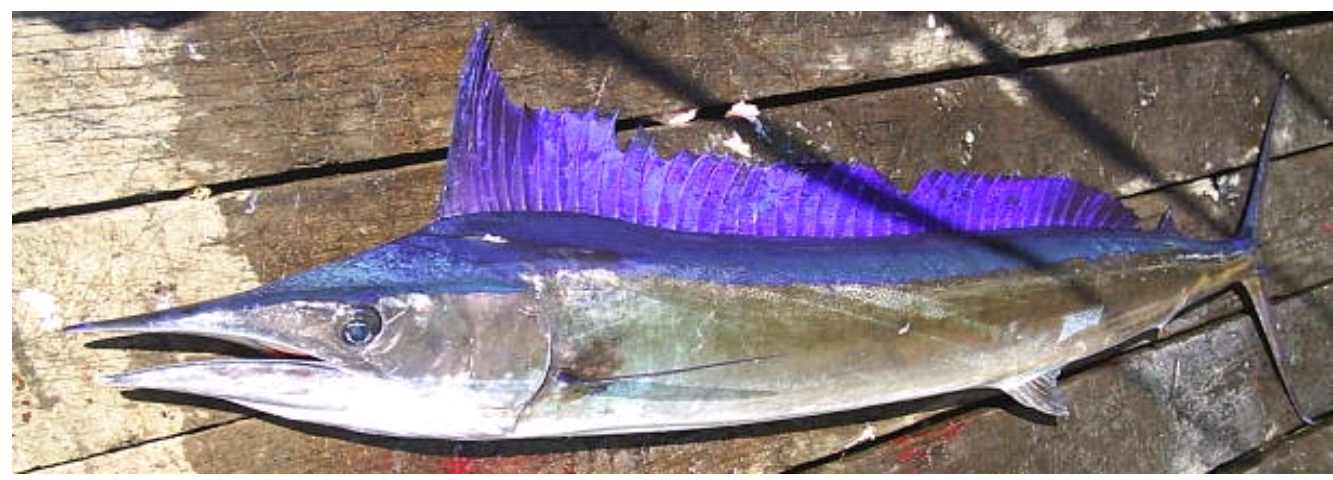

Gambar 1. Ikan todak berparuh pendek.

Figure 1. Shortbill spearfish.

\section{Komposisi Ukuran Panjang Ikan Todak Berparuh} Pendek

Ukuran ikan todak berparuh pendek yang diamati memiliki kisaran panjang tubuh antara 135-175 cmLJFL dengan panjang maksimal $175 \mathrm{cmLJFL}$ dan modus pada kisaran 155-165 cmLJFL (Gambar 2). Ikan todak berparuh pendek yang tertangkap oleh tuna longline di Samudera Hindia dapat dikatakan memiliki ukuran yang cukup panjang. Menurut Nakamura (1985), panjang maksimum yang diketahui dari spesies ini sekitar $230 \mathrm{cmTL}$ dengan bobot $52 \mathrm{~kg}$. Panjang rata-rata ikan ini yang merupakan hasil tangkapan perikanan tuna longline di Samudera Pasifik Selatan bagian tengah sekitar 135 dan 150 cmFL di Samudera Pasifik bagian timur dengan bobot sekitar $18 \mathrm{~kg} /$ ekor.

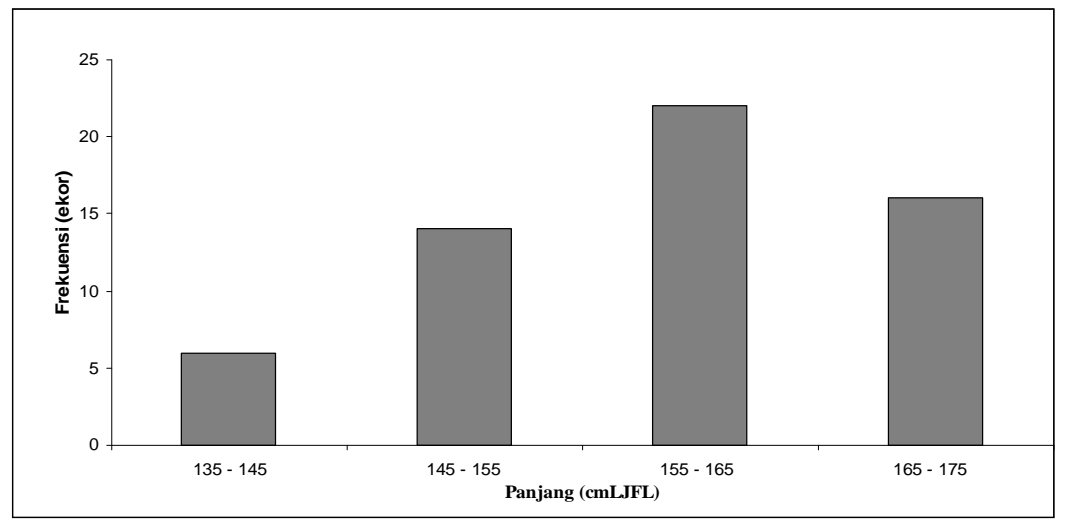

Gambar 2. Distribusi frekuensi panjang ikan todak berparuh pendek hasil tangkapan tuna longline di Samudera Hindia pada bulan September sampai Desember 2008.

Figure 2. $\quad$ Length frequency distribution of shortbill spearfish caught by tuna longline in Indian Ocean in September until December 2008. 


\section{Perbandingan Jenis Kelamin}

Perbandingan jenis kelamin (sex ratio) adalah suatu angka yang menunjukan perbandingan jumlah individu jantan dan betina dalam suatu populasi. Variasi dalam perbandingan kelamin sering terjadi dikarenakan tiga faktor yaitu perbedaan tingkah laku seks, kondisi lingkungan, dan penangkapan (Bal \& Rao, 1984). Pendugaan rasio jenis kelamin sangat dibutuhkan sebagai bahan pertimbangan dalam produksi, rekruitmen, dan konservasi sumber daya ikan tersebut (Sukimin et al., 2002).

Dari pengamatan terhadap 58 ekor ikan todak berparuh pendek diperoleh hasil bahwa empat ekor berkelamin jantan dan 54 ekor berkelamin betina. Hasil ini menunjukan perbandingan kelamin ikan todak berparuh pendek 1:13,5. Berdasarkan atas hasil uji chi-square secara keseluruhan diperoleh bahwa hasil sangat berbeda nyata di mana $c$ hitung $>c$ tabel $\left(c^{2}=8,45 ; c^{2}\right.$ tabel $\left.\right|_{(0,05)}=3,481 ; c^{2}$ tabel $\left.{ }_{(0,01)}=6,635\right)$, dengan demikian dapat disimpulkan bahwa perbandingan jenis kelamin jantan dan betina dalam keadaan tidak seimbang.

\section{Tingkat Kematangan Gonad}

Tingkat kematangan gonad adalah tahap tertentu perkembangan gonad sebelum dan sesudah ikan memijah (Effendie, 1979). Penentuan tingkat kematangan gonad sangat penting dilakukan, karena sangat berguna untuk mengetahui perbandingan antara gonad yang masak dengan stok yang ada di perairan, ukuran pemijahan, musim pemijahan, dan lama pemijahan dalam suatu siklus (Sukimin et al.,
2002). Penentuan tingkat kematangan gonad dapat dilakukan dengan dua cara yaitu secara morfologis (visual) dan secara histologis. Untuk pengamatan terhadap tingkat kematangan gonad ikan todak berparuh pendek di perairan Samudera Hindia dilakukan secara morfologis (visual).

Pengamatan secara visual terhadap gonad ikan todak berparuh pendek yang tertangkap diperoleh empat tingkat yaitu tingkat kematangan gonad II, III, IV, dan V. Pada Gambar 3 terlihat bahwa pada bulan September ikan todak berparuh pendek betina didominansi oleh tingkat kematangan gonad II sebesar $66,7 \%$, bulan Oktober didominansi oleh tingkat kematangan gonad $V$ sebesar $46,2 \%$, bulan Nopember didominansi oleh tingkat kematangan gonad II sebesar $53,3 \%$, sedangkan pada bulan Desember didominansi oleh tingkat kematangan gonad III sebesar $42,9 \%$. Pada bulan Nopember sampai Desember terlihat bahwa tingkat kematangan gonad IV mulai berkurang. Hal ini menunjukan bahwa pada bulan Nopember sampai Desember diduga banyak ikan todak berparuh pendek betina yang sudah memijah (spawned).

Musim memijah ikan todak berparuh pendek sebagian besar diduga terjadi pada musim dingin, terutama di perairan yang berarus hangat dengan suhu permukaan perairan berkisar $25^{\circ} \mathrm{C}$. Ikan ini pernah tertangkap di sekitar perairan Pulau Taiwan dengan tingkat kematangan gonad tingkat VI di bulan Nopember. Ikan todak berparuh pendek betina yang siap memijah juga dilaporkan berlangsung selama musim dingin di perairan bagian barat Samudera Hindia dan bulan Maret di perairan Samudera Pasifik bagian tengah (Nakamura,1985).

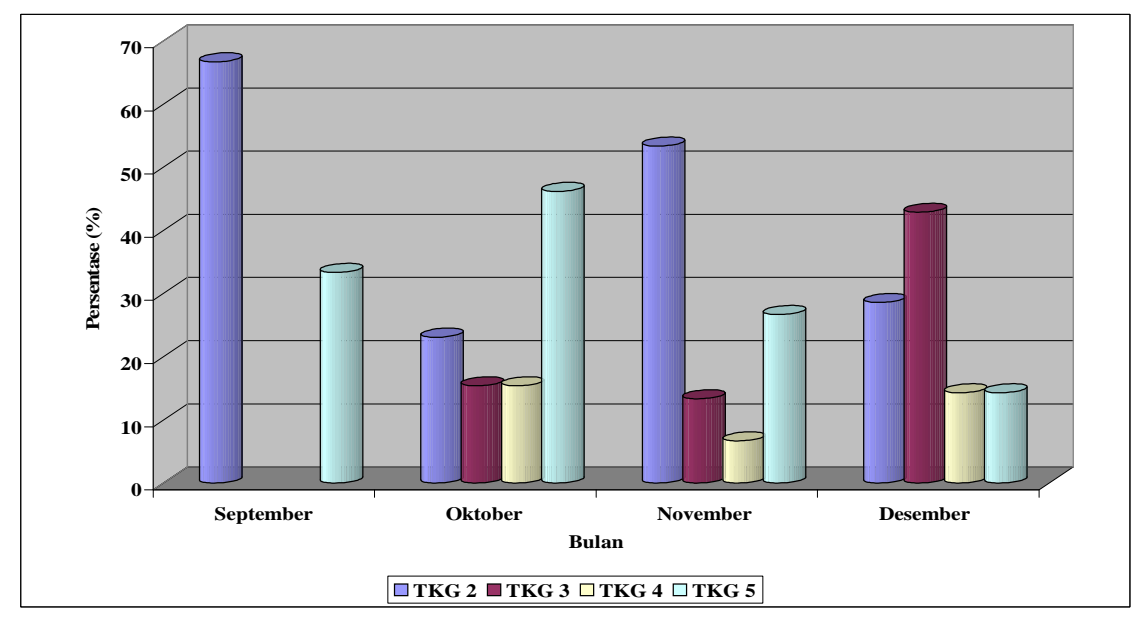

Gambar 3. Persentase tingkat kematangan gonad ikan todak berparuh pendek hasil tangkapan tuna $\begin{array}{ll} & \text { Iongline pada bulan September sampai Desember } 2008 \text { di Samudera Hindia. } \\ \text { Figure 3. The percentage of gonad maturity of shortbill spearfish caught by tuna longline in Indian }\end{array}$ Ocean, September until December 2008. 


\section{Daerah Penangkapan}

Daerah penangkapan kapal tuna longline yang berbasis di Benoa bergantung pada sasaran produksi yaitu tuna segar (fresh tuna) seperti ikan tuna mata besar (Thunnus obesus) dan madidihang (Thunnus albacares), serta tuna beku (frozen tuna) seperti albakor (Thunnus alalunga), marlin (Makaira sp. dan Tetrapturus sp.) dan ikan pedang (Xiphias gladius). Daerah penangkapan tuna segar di perairan Samudera Hindia sebelah selatan Sumbawa sampai selatan Yogyakarta. Kadang-kadang mencapai perairan di sebelah selatan Pulau Christmas dan sampai perbatasan perairan Australia serta bagian utara di perairan Laut Banda dengan lama operasi penangkapan 2-4 bulan per trip. Daerah penangkapan ikan tuna sebagai bahan tuna beku (frozen tuna) mencapai perairan sebelah barat Australia sampai ke perairan selatan Srilangka dan Maladewa dengan lama operasi antara 7-12 bulan per trip.

Selama penelitian dilakukan ikan todak berparuh pendek yang tertangkap di perairan Samudera Hindia berada pada posisi geografi antara $75,996^{\circ}-81,010^{\circ}$ BT dan $16,068^{\circ}-19,025^{\circ}$ LS (Gambar 4). Daerah penangkapan tersebut terletak di sebelah selatan Srilangka dan Maladewa, bukan Zona Ekonomi Eksklusif kedua negara tersebut dan merupakan laut lepas (high seas) di Samudera Hindia.

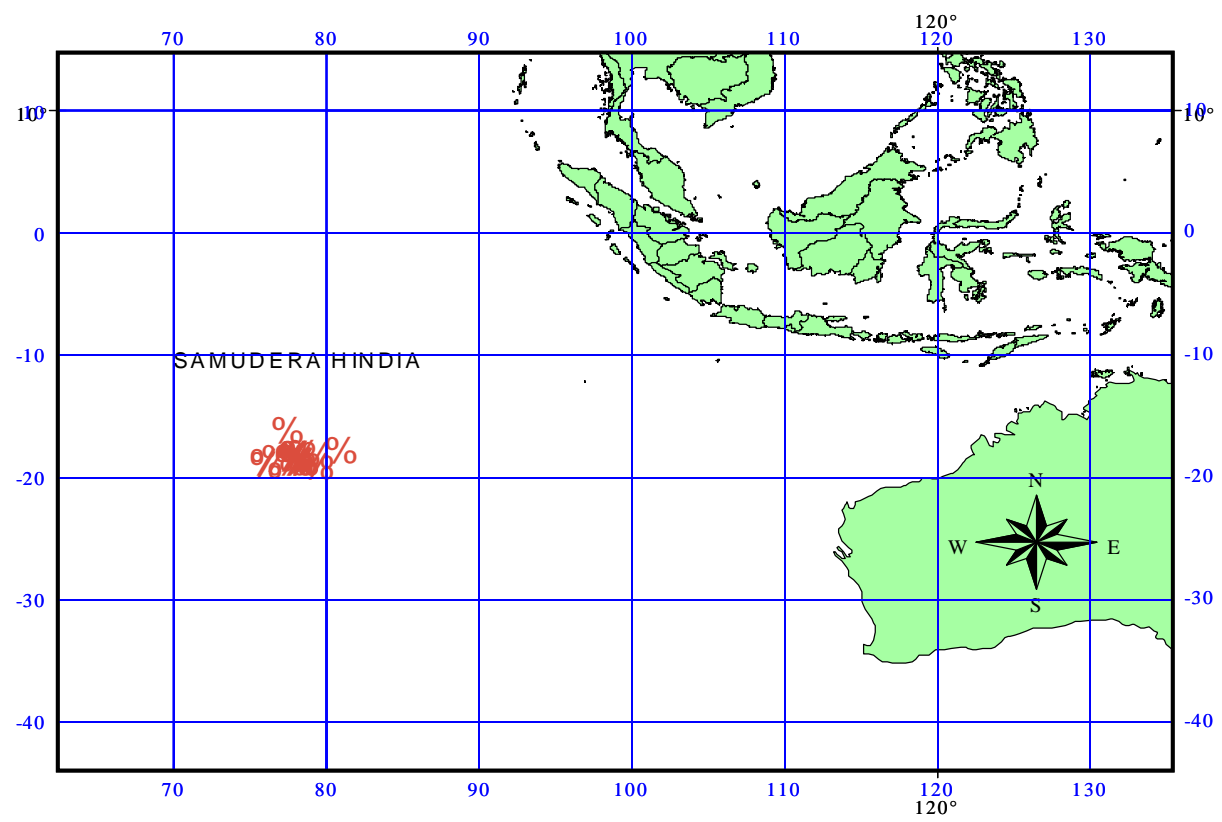

Gambar 4 Daerah penangkapan ikan todak berparuh pendek di Samudera Hindia.

Figure 4. Fishing ground of shortbill spearfish in Indian Ocean.

\section{KESIMPULAN}

1. Ikan todak berparuh pendek yang tertangkap oleh tuna longline di Samudera Hindia memiliki ukuran antara $135-175 \mathrm{cmLJFL}$ dengan panjang maksimal $175 \mathrm{cmLJFL}$ dan modus pada kisaran 155-165 cmLJFL.

2. Perbandingan kelamin ikan jantan dan betina $1: 13,5$ dan dalam keadaan tidak seimbang.

3. Ikan todak berparuh pendek yang tertangkap pada bulan Nopember sampai Desember 2008 menunjukan tingkat kematangan gonad $\mathrm{V}$ mulai berkurang, yang mengindikasikan pada saat itu banyak ikan todak berparuh pendek betina yang sudah memijah.

\section{PERSANTUNAN}

Tulisan ini merupakan kontribusi dari kegiatan riset program observer tuna Samudera Hindia pada kapalkapal tuna longline di Pelabuhan Benoa, T. A. 20052009, kerja sama antara Pusat Riset Perikanan Tangkap dengan Australian Centre for International Agricultural Research-Australia.

\section{DAFTAR PUSTAKA}

Bal, D. V. \& K. V. Rao. 1984. Marine Fisheries. Tata Mc. Graw-Hill Publishing Company Limited. New Delhi. 5-24.

Effendie, M. I. 1979. Metoda Biologi Perikanan. Yayasan Dewi Sri. Bogor. 112 pp. 
Effendie, M. I. 1997. Biologi Perikanan. Yayasan Pustaka Nusatama. Yogyakarta. 163 pp.

Nakamura, I. 1985. FAO species catalogue. Vol. 5. Billfishes of the World. An Annotated and Illustrated Catalogue of Marlins, Sailfishes, Spearfishes, and Swordfishes Known to Date. FAO Fish. Synop. (125) Vol. 5. FAO. Rome. 65 pp.

Pepperell, J. G. \& P. Grewe. 1998. A Field Guide to the Indo-Pacific Billfishes. CSIRO Division of Marine Research. Hobart. 16 pp.
Sukimin, S., S. Isdrajat, \& Yon Vitner. 2002. Petunjuk Praktikum Biologi Perikanan. Fakultas Perikanan dan Ilmu Kelautan. Institut Pertanian Bogor. Bogor.

Sugiyono. 2004. Statistik Non Parametris untuk Penelitian. Penerbit CV. Alfabeta Bandung. 158 pp.

Uktolseja, J. C. B., R. Purwasamita, K. Susanto, \& A. B. Sulistiadji. 1989. Sumber daya ikan pelagis besar. In Widodo, J., K. A. Aziz, B. E. Priyono, G. H. Tampubolon, N. Naamin, \& A. Djamali (eds). Potensi dan Penyebaran Sumber Daya Ikan Laut di Perairan Indonesia. Komisi Nasional Pengkajian Stok Sumber Daya Ikan Laut. Jakarta. 40-88. 